\title{
The Study of Leaves in Plantations of Poplar and Alder in Fouman Region of Iran
}

\author{
${ }^{1 *}$ Seyed Abdollah Mousavi Koupar, ${ }^{2}$ Seyed Mohsen Hosseini, \\ ${ }^{3}$ Farzam Hosseinzadeh Rad
}

${ }^{1}$ Assistant Professor, Agricultural and Natural Resources Research and Education Center of Gilan province, Rasht

${ }^{2}$ Associate Professor, Tarbiat Modares University, Noor, Iran

${ }^{3}$ Researcher, Agricultural and Natural Resources Research and Education Center of Gilan province, Rasht, Iran

1 *abdy_mo@yahoo.com

\begin{abstract}
Fertility of soil is reduced by unmixed forest planting as a result continuity of production will be stopped. One of the existing resolutions is mixed forest-planting along with stabilizing species. In this survey nutritional elements existing in senescent and living leaves of two species-populous deltoids and Alnus glutinosa- has been investigated, in mixed and unmixed forest-planting in a completely randomized block in Fouman, Guilan. The sampling was done on September. Samples had been dried at $70^{\circ} \mathrm{c}$. Total amount of nitrogen was measured by cajoled-L device by percentage. Phosphurs, Calsium, Potassium and magnesium is measured by absorption method with spectrophotometer device. The measured amount of nitrogen in senescent and living leaves of Alnus glutinosa is more than populous deltoids, while there is not a meaningful difference between the measured phosphors in living and senescent leaves of Alnus glutinosa and populous deltoids. Living and senescent leaves of populous deltoids in mixed controls accompanying Alnus glutinosa shows higher amount of nitrogen compare with unmixed controls that indicates effective role of Alnus glutinosa in nitrogen absorption. In general mixture planting of Alnus glutinosa and populous deltoids is effectively impact on forest - planting and forest conditions.
\end{abstract}

Keywords: planting, nutriment, nutritional element, populous deltoid, Alnus glutinosa

\section{INTRODUCTION}

In short periods of usage, the nutritional value of soil may be reduced (Khanna, 1997). As a result, forest planting production rely on nutritional value of soil; and as it seems management activities and species can change it (Binkley et al., 2000) .Utilizing a new system of forest planting is necessary .Because of fertility decrease of soil, discontinuous production of forest planting, in the long run; especially in fast - growing species; nitrogen stabilizing trees are used in forest planting (Rhoades, Binkley ,1996). They produce high measures of nitrogen that suits for restoring soil's nitrogen, the cause of this shortage is continuous usage (Khanna, 1997) and high speed of leaves' corruption (Parrotta,1999) .Additionally each species has a special nutritional need and cycle, perhaps they require less nutritional material of soil than unmixed species (Montagnini,2000). Main purposes of the study are to investigate the amount of return of nutriment of nutritional elements by Alnus glutinosa and populus deltoids's leaves in mixed and unmixed forest planting, and to measure the amount of nutritional elements and the return of elements by senescent and living leaves of Alnus glutinosa and populus deltoids in unmixed and mixed forest - planting.

\section{Methods AND MATERIAlS}

\subsection{Site Characteristics}

The study area is located at the Foman experiment station, in Guilan province, on the northern parts of Iran $\left(35^{\circ} 5^{\prime} \mathrm{N}, 49^{\circ} 15^{\prime} \mathrm{E}\right)$. Experimental plots were located at an altitude of $10 \mathrm{~m}$ above sea level and with low slope $(0-3 \%)$. Annual rainfall averages $1260.1 \mathrm{~mm}$, with wetter months occurring between September and February, and a dry season from April to August monthly rainfall usually averages < $40 \mathrm{~mm}$ for 4 months. Average daily temperatures range from $11.3 \circ \mathrm{C}$ in February to $29.2 \circ \mathrm{C}$ in 
August. The soils are well-drained, and have a silty loam texture with a $\mathrm{pH}$ 4.8-5.9. Previously (approximately 50 years ago) this area was dominated by natural forests containing native tree species such as Quercus castaneifolia C.A.Meyer., Gleditschia caspica Desp., Carpinus betulus L., etc. The surrounding area is dominated by agricultural fields and commercial building.

\subsection{Experimental Design}

Experimental plantations were established in 1996 using a randomized complete block design that included four replicate $40 \mathrm{~m} \times 40 \mathrm{~m}$ plots of each of the following treatments:

(i) $70 \%$ P. deltoides $+30 \%$ A. subcordata(70P:30A),

(ii) 50\% P. deltoides + 50\% A. subcordata(50P:50A),

(iii) $30 \%$ P. deltoides $+70 \%$ A. subcordata(30P:70A),

(iv) Populus deltoides (100P),

(v) Alnus subcordata (100A),

Tree spacing within plantations was $4 \mathrm{~m} \times 4 \mathrm{~m}$ and tow species were systematically mixed within rows.

\subsection{Methods}

Leaf sampling was done on September and for every single species. There were 6 trees of every species in each sample section, in this way, 2 trees in the center and other 4 trees occupy each corner of the section. Leaf samples were collected from 1/3 of lower crown of each tree and main branches. Senescent leaves sampling was done in every sample section and for each species, as recent fallen leaves were gathered before corruption. Senescent leaves were collected after initial collection of leaves in consecutive days to make sure that leaves had been fallen recently. After that, samples were transported to lab and dried in oven at $70^{\circ} \mathrm{c}$ then were grind.

Total measured amount of nitrogen by Kaljald L device is expressed by percentage. Phosphurs is measured by spectrophotometer by Atomic absorption method and so potassium, calcium and magnesium (all results is expressed by percentage).

\subsection{Analyzing Method}

Resulting data were analyzed using sas computer program with design framework as totally random blocks. Variation analyze is used for general comparison, and for multiple comparison Tukey-HSD test is utilized.

\section{RESUlts}

Amount of nitrogen in living and senescent of populous deltoides in mixed treatments with Alnus glutinosa is higher than unmixed treatment; while mixed treatment shows no difference (Fig.1,2). There is a meaningful difference between amount of phosphors existing in senescent leaves of populous deltoides in $70 \%$ mixed treatment and other treatments of poplar (Fig.4). There isnt a meaningful difference between existing potassium in living and senescent leaves of populous deltoides in unmixed treatment and others. (Fig. 5, 6).

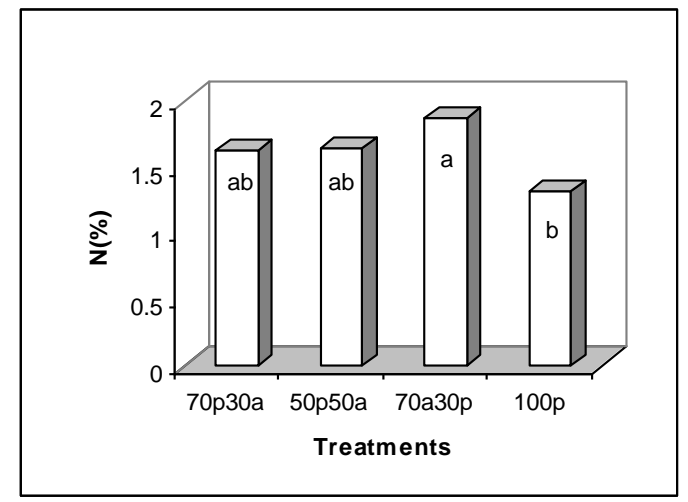

Fig1. The amount of nitrogen in living leaves of Poplar. The letters on different column indicate a different comparison. 


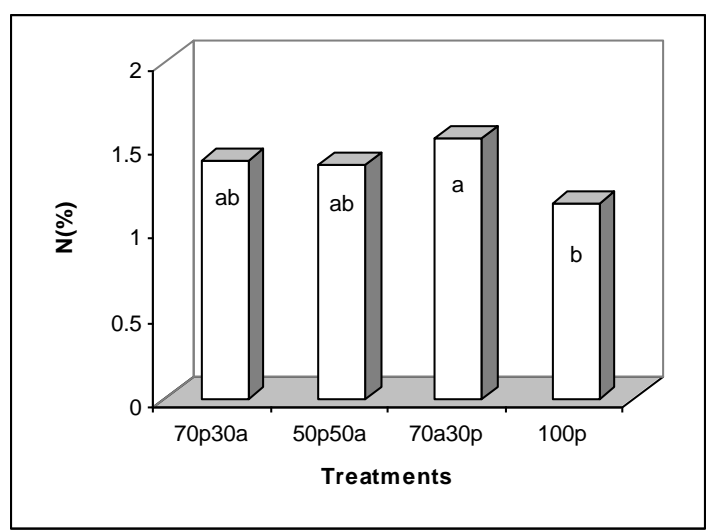

Fig2. The amount of nitrogen in senescent leaves of Poplar. The letters on different column indicate a different comparison.

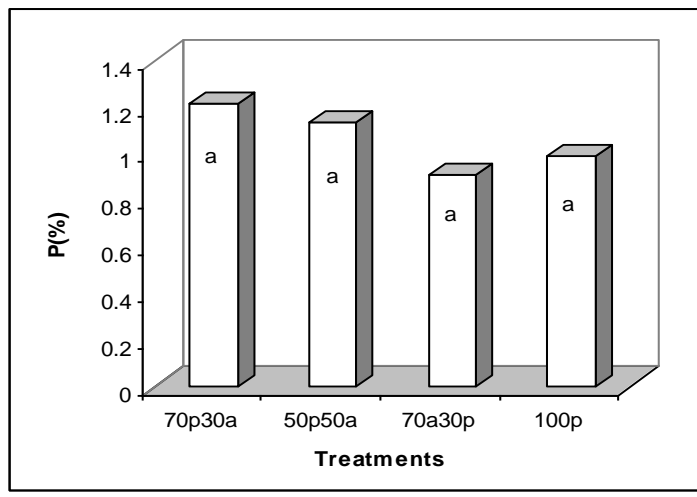

Fig3. The amount of phosphor in living leaves of Poplar. The letters on different column indicate a different comparison.

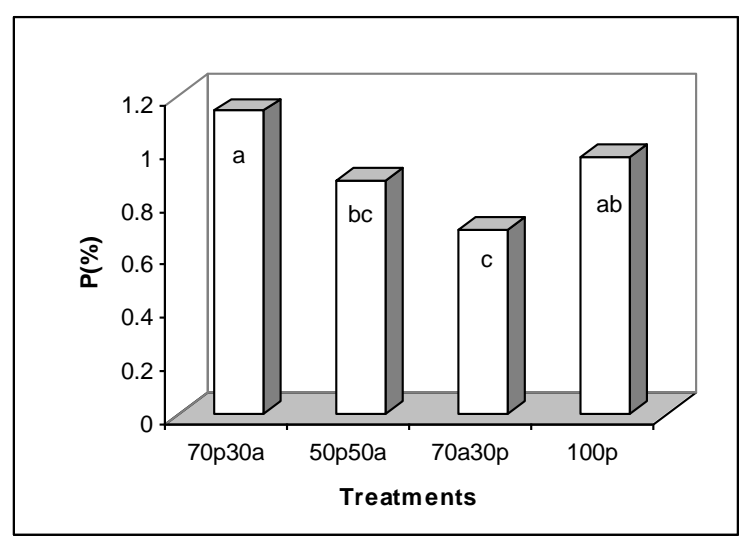

Fig4. The amount of phosphor in senescent leaves of Poplar. The letters on different column indicate a different comparison.

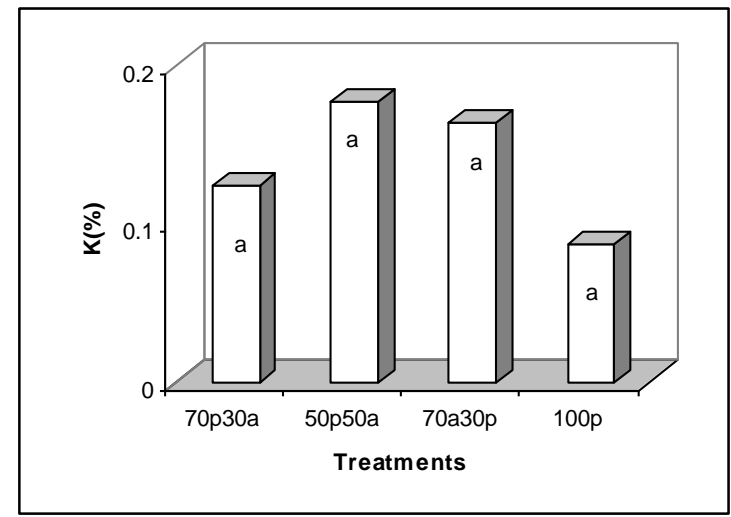

Fig5. The amount of potassium in living leaves of Poplar. The letters on different column indicate a different comparison. 


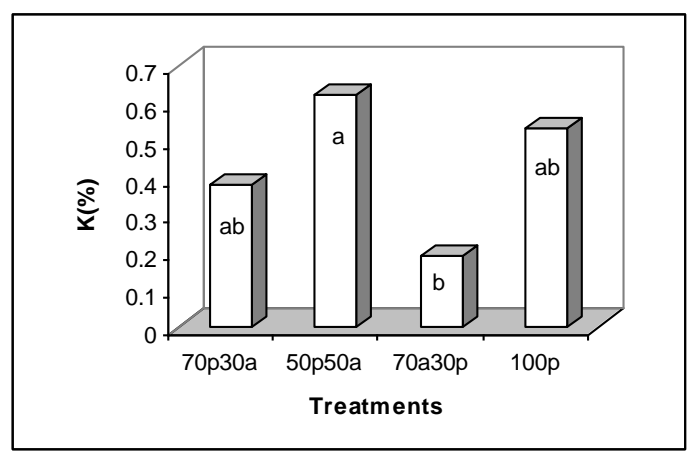

Fig6. The amount of potassium in senescent leaves of Poplar. The letters on different column indicate a different comparison.

\section{DisCUSSIONS}

The measured amount of nitrogen in living and senescent leaves in populus deltoides is less than Alnus glutinosa so Alnus glutinosa absorbs more nitrogen than Poplar and as a result it returns more of it to soil. It is likely because Alnus glutinosa is a nitrogen stabilizing species.

Sayyad et al.(2006) founded that existing nitrogen in living and senescent leaves of Alnus subcordata is more than populus deltoides. Parrotta(1999) also came to the conclusion that nitrogen stabilizing species return higher amount of nitrogen by their leaves. Montagnini (2000) showed existing nitrogen in leaves of nitrogen stabilizing species is more than others. The existing nitrogen in living and senescent leaves of populus deltoides in mixed treatments with Alnus glutinosa is more than nitrogen in living and senescent leaves of unmixed treatment of populus deltoides .It reveals that Alnus glutinosa is effective in nitrogen absorption by populus deltoides and accompanying its return to soil by senescent leaves of populus deltoides in mixed treatments. Sayyad et al. (2006) compared mixed and unmixed forest -planting of populus deltoides and Alnus subcordata and came to the result that existing nitrogen in living and senescent leaves of populus deltoides in mixed treatments with Alnus subcordata is more than unmixed treatment, while no difference is shown in mixed treatments (Khanna , 1998) detected no difference between living leaves of eucalyptus in unmixed forest planting and mixed forest planting with acacia, while, just like the present study, senescent leaves of nitrogen stabilizing species (eucalyptus ) mixed forest planting along with acacia is more that unmixed forest planting. Montagini (2000)

Observed that among 3 species with unstabilizing quality, only the amount of nitrogen in leaves of one of them in mixed forest planting with nitrogen stabilizing species has been increased. Populus deltoides has no effect on nitrogen absorption by Alnus glutinosa's leaves and their return to soil by leaves because amount of nitrogen in living and senescent leaves in unmixed and mixed with populus deltoides shows no difference Khanna (1997) observed no difference between existing nitrogen in living and senescent leaves of acacia in mixed and unmixed treatments.

Concerning nitrogen stabilizing species as acacia, Khanna (1998) concluded similarly, there was no difference between living and senescent leaves, while Parrotta (1999) observed higher amount of nitrogen in living and senescent leaves of nitrogen stabilizing species and main species in mixed treatment in comparison to unmixed.

The amount of phosphors existing in living leaves of Alnus glutinosa and populus deltoides have no meaningful difference. It can be concluded that regarding absorption and return of this element at this particular age and time, there is no difference. But existing phosphors in senescent leaves of Alder and Poplar has meaningful difference. Sayyad et al. (2006) showed that phophurs in living and senescent leaves of Alnus subcordata and populus deltoides has no meaningful difference.

Montagnini (2000) observed higher amount of phosphors in leaves on stabilizing species in comparison to non-stabilizing species.

Equal amount of phosphors in living and senescent leaves of populus deltoides shows that mixture of two species has no effect on absorption of living leaves and its return by senescent leaves.

Montagnini (2000) also distinguished no difference between existing phosphors in leaves of stabilizing species and non-stabilizing ones in unmixed forest planting comparing with mixed planting. 
Khanna $(1997,98)$ observed higher amount of phosphors in living leaves of non stabilizing species eucalyptus - and living and senescent leaves of acacia in unmixed treatment compare with mixed treatments ,but in case of senescent leaves of eucalyptus there is no meaningful difference between unmixed and mixed treatments. As a matter of fact parratta (1999) detected higher amount of phosphors in senescent leaves of nitrogen stabilizing species and main species in mixed treatment than unmixed.The amount of existing potassium in living leaves of Alnus glutinosa is distinguishly higher than populus deltoides in unmixed forest planting. But potassium in senescent leaves of Alnus glutinosa and populus deltoides in mixed forest planting has no meaningful difference. It shows that the two species considering return of element in this particular age and time are alike.

Montagnini (2000) observed higher amount of potassium in stabilizing species than no stabilizing ones. There is a meaningful difference between amount of potassium in living leaves of Alnus glutinosa and populus deltoides in mixed and unmixed treatments that reveals these two species contribute each other to absorb nitrogen by living leaves. But equal absorption of potassium in senescent leaves of Alnus glutinosa in mixed and unmixed treatments shows the mixture of the 2 species has no effect on return of this element by senescent leaves while in populus deltoides the difference between amount of potassium in senescent leaves of populus deltoides in mixed and unmixed treatments shows that the mixture of the two species has no significant effect on return of the element by senescent leaves of populus deltoides.

Montagnini (2000) detected no difference between the amount of existing potassium in living leaves of nitrogen stabilizing species and non-stabilizing ones. In mixed and unmixed forest planting parrotta (1999) observed higher amount of potassium in senescent leaves of 2 nitrogen stabilizing species and main species in mixed treatment and unmixed.

\section{REFERENCES}

[1] Binkley, D., Giardian, Ch. and Bashkin, M. A. 2000. Soil phosphorus pools and supply under the influence of Ecalyptus saligna and nitrogen-fixing Albizia falcataria .For. Ecol. and Manage. 128: 241-247pp.

[2] Khanna, P. K. 1997. Comparison of growth and nutrition of young monocultures and mixed stands of Eucalyptus globulus and Acacia mearnsii. For. Ecol. and Manage. 94:105-113pp.

[3] Khanna, P.K.1998. Nutrient cycling under mixed-species tree systems in south east Asia. Agroforestry Systems, 38, 99-120 pp.

[4] Montagnini, F. 2000. Accumulation $\ln$ above-ground biomass and soil storage of mineral nutrients in pure and mixed plantations in a humid tropical lowland. For. Ecol. and Manage. 134: 257-270pp.

[5] Parrotta, J. A. 1999. Prodactivity, nutrient cycling, and succession in single- and mixed-species plantations of Casuarina equisetifolia, Eucalyptus robusta, and Leucaena leucocephala in Puerto Rico. For. Ecol. and Manage. 124:45-77pp.

[6] Rhoades, C. and Binkley, D. 1996. Factors influencing decline in soil pH in Hawaiian Eucalyptus and Albizia plantations. For. Ecol. and Manage. 80: 47-56 pp.

[7] Sayyad,E.Hosseini,S.M,Mokhtari,J.,Mahdavi,R.,Jalali,S.G.,Akbarinia,M.,and Tabari,M.(2006)Comparision of growth, nutrition and soil properties of pure and mixed stands of Populus deltoids and Alnus subcodata.Silva Fennica 40(1):27-35. 